\title{
Pengaruh Kedisiplinan Belajar dan Motivasi Belajar terhadap Prestasi Belajar Siswa di SMA Muhammadiyah Maumere
}

\author{
Vicky Zulfikar Wahab ${ }^{1}$, Nurdin H. Abd. Rahman ${ }^{2}{ }^{2}$, Mohammad Fitri ${ }^{3}$ \\ ${ }^{1}$ Pendidikan Ekonomi, IKIP Muhammadiyah Maumere \\ e-mail: vickhyzulvhy021@gmail.com \\ 2Pendidikan Ekonomi, IKIP Muhammadiyah Maumere \\ e-mail: nurdinrahman811@gmail.com \\ 3Pendidikan Ekonomi, IKIP Muhammadiyah Maumere \\ e-mail: zimbonokelagi@gmail.com
}

\begin{abstract}
The purpose of this study was to determine the effect of learning discipline and learning motivation toward student achievement at SMA Muhammadiyah Maumere, both partially and simultaneously. The research using the Ex-Post Facto method. The research subject was students of SMA Muhammadiyah Maumere amounted to 250 students with a sample of 153 students. Data was collected through questionnaire and documentation as well as data analysis using multiple linear regression analysis. The conclusion: 1) Learning discipline did not significant effect toward student achievement at SMA Muhammadiyah Maumere. 2) Learning motivation have a negative and significant effect toward student achievement at SMA Muhammadiyah Maumere. 3) Learning discipline and learning motivation simultaneously have a significant influence toward student achievement at SMA Muhammadiyah Maumere.
\end{abstract}

Keywords: Discipline, Motivation, Achievement

\begin{abstract}
Abstrak
Tujuan penelitian ini untuk mengetahui pengaruh kedisiplinan belajar dan motivasi belajar terhadap prestasi belajar siswa di SMA Muhammadiyah Maumere, baik secara parsial maupun simultan. Penelitian ini menggunakan metode Ex-Post Facto. Subjek penelitian adalah siswa SMA Muhammadiyah Maumere berjumlah 250 siswa dengan sampel penelitian sebanyak 153 siswa. Data dikumpulkan melalui angket dan dokumentasi serta analisis adat menggunakan analisis regresi linear berganda. Kesimpulannya: 1) Kedisiplinan belajar tidak berpengaruh signifikan terhadap prestasi belajar siswa di SMA Muhammadiyah Maumere. 2) Motivasi belajar berpengaruh negatif dan signifikan terhadap prestasi belajar siswa di SMA Muhmmadiyah
\end{abstract}


Maumere. 3) Kedisiplinan belajar dan motivasi belajar secara bersamaan berpengaruh signifikan terhadap prestasi belajar siswa di SMA Muhammadiyah Maumere.

Kata kunci : Kedisiplinan, Motivasi, Prestasi

\section{PENDAHULUAN}

Pendidikan merupakan bimbingan atau pertolongan yang diberikan oleh orang dewasa kepada perkembangan anak untuk mencapai kedewasaannya dengan tujuan agar anak cukup cakap melaksanakan tugas hidupnya tidak dengan bantuan orang lain (Feni, 2014). Seseorang yang memiliki pendidikan maka ia akan mampu mengembangkan seluruh aspek kepribadian miliknya yang meliputi nilai sikap, pengetahuan dan keterampilan. UU SISDIKNAS No 20 Tahun 2003 menyatakan "Pendidikan adalah usaha sadar dan terencana untuk mewujudkan suasana belajar dan proses pembelajaran agar peserta didik secara aktif mengembangkan potensi dirinya untuk memiliki kekuatan spiritual keagamaan, pengendalian diri, kepribadian, kecerdasan, akhlak mulia, serta keterampilan yang diperlukan dirinya, masyarakat, bangsa dan negara. Pendidikan nasional berfungsi mengembangkan kemampuan dan membentuk watak serta peradaban bangsa yang bermartabat dalam rangka mencerdaskan kehidupan bangsa, bertujuan untuk berkembangnya potensi peserta didik agar menjadi manusia yang beriman dan bertakwa kepada Tuhan Yang Maha Esa, berakhlak mulia, sehat, berilmu, cakap, kreatif, mandiri, dan menjadi warga negara yang demokratis serta bertanggung jawab" (Depdiknas, 2003).

Pendidikan dilaksanakan melalui pembelajaran yang sudah dirancang, diharapkan agar siswa mampu mengoptimalkan kemampuan dan kapasitas yang dimilikinya. Dengan demikian, dalam melakukan perbaikan disegala lini ruang lingkup pendidikan, pendidikan dituntut untuk terus berkembang dan berinovasi. Tercapainya tujuan pendidikan nasional tersebut jika ada kerjasama dari semua pihak. Sehingga untuk membantu orang tua dalam mendidik anaknya perlu adanya suatu lembaga pendidikan. Usaha tersebut harus dilakukan agar tujuan pendidikan 
diatas dapat tercapai. Keberhasilan siswa dalam proses pendidikan dapat diukur melalui prestasi belajar. Marsun dan Martaniah dalam (Hidayat, 2013: 83) berpendapat bahwa "Prestasi belajar merupakan hasil kegiatan belajar, yaitu sejauh mana peserta didik menguasai bahan pelajaran yang diajarkan, yang diikuti oleh munculnya perasaan puas bahwa ia telah melakukan sesuatu dengan baik". "Prestasi dapat diukur dengan menggunakan tes prestasi, yaitu ujian yang dimaksudkan untuk mengukur apa yang telah dipelajari oleh siswa atau keterampilan apa yang telah dikuasai oleh siswa" (Santrock, 2009). Akan tetapi, tinggi rendahnya prestasi belajar yang diraih siswa terdapat faktor lain yang mempengaruhi selain proses pengajaran itu sendiri.

Menurut Moenir dalam (Chulsum, 2017) bahwa "Disiplin merupakan bentuk kepatuhan terhadap peraturan dan tata tertib. Disiplin memiliki dua indikator yaitu disiplin dalam waktu dan disiplin dalam perbuatan". "Disiplin belajar memiliki beberapa fungsi antara lain: membiasakan diri dan meningkatkan kesadaran diri para siswa untuk lebih mematuhi peraturan, menjadikan proses pembelajaran lebih kondusif dan dapat bermanfaat saat siswa nanti terjun di kehidupan bermasyarakat" (Tu'u, 2004), Namun pada kenyataannya di lapangan tidak selamanya sesuai dengan harapan sekolah. Kurangnya disiplin belajar siswa di SMA Muhammadiyah Maumere terlihat dari sikap dan tindakannya mengabaikan tanggung jawabnya sebagai pelajar. Hal tersebut menyebabkan pencapaian prestasi belajar siswa di SMA Muhammadiyah Maumere belum optimal. Berikut hasil belajar siswa di SMA Muhammadiyah Maumere:

Tabel 1. Hasil Belajar Siswa SMA Muhammadiyah Maumere

\begin{tabular}{|c|c|c|c|c|c|c|c|c|}
\hline \multirow{2}{*}{$\begin{array}{l}\text { Total } \\
\text { Siswa }\end{array}$} & \multirow[t]{2}{*}{ KKM } & \multicolumn{7}{|c|}{ Rata-rata Rapor } \\
\hline & & Kurang & & кup & & & & Sekali \\
\hline 250 & 70 & $5 \quad 2,00 \%$ & 127 & $50,80 \%$ & 73 & $29,20 \%$ & 45 & $18,00 \%$ \\
\hline
\end{tabular}

Sumber: Data SMA Muhammadiyah Maumere

Berdasarkan tabel hasil belajar siswa di SMA Muhammadiyah Maumere diatas terlihat dari total 250 siswa, rata-rata hasil belajar siswa hanya mencapai standar lulusan. "Dalam kegiatan belajar, motivasi dapat dikatatakan sebagai 
keseluruhan daya penggerak di dalam diri siswa yang menimbulkan kegiatan belajar, yang menjamin kelangsungan dari kegiatan belajar dan yang memberikan arah pada kegiatan belajar, sehingga tujuan yang dikehendaki oleh subjek belajar itu dapat tercapai" (A.M, 2011:73). "Motivasi belajar tidak hanya jadi pendorong untuk mencapai hasil yang baik tetapi mengandung usaha untuk mencapai tujuan belajar, dimana terdapat pemahamn dan pengembangan dari belajar" (Hadinata, 2009). Di SMA Muhammadiyah Maumere, gejala kurangnya motivasi belajar siswa ditunjukan dengan adanya siswa yang tidak mengikuti mata pelajaran. Meskipun sudah mendapat teguran dari guru tetapi masih ada yang tidak mengikuti pelajaran dengan berbagai alasan. Selain itu, masih ada siswa yang tidak disiplin menyelesaikan tugas serta kurang memperhatikan materi yang dijelaskan bahkan ada siswa yang harus mengikuti ujian perbaikan dikarenakan memperoleh nilai dibawah standar.

Permasalahan tersebut yang melatarbelakangi penulis melakukan penelitian tentang "Pengaruh Kedisiplinan Belajar Dan Motivasi Belajar terhadap Prestasi Belajar Siswa di SMA Muhammadiyah Maumere". Penelitian ini bertujuan untuk mengetahui pengaruh kedisiplinan belajar dan motivasi belajar terhadap prestasi belajar siswa di SMA Muhammadiyah Maumere, baik secara parsial maupun simultan.

\section{METODE PENELITIAN}

Penelitian ini dilakukan menggunakan metode Ex-Post Facto melalui pendekatan kuantitatif. Metode Ex-Post Facto adalah "Suatu penelitian yang bertujuan untuk meneliti peristiwa yang telah terjadi, kemudian mengulas kembali untuk mengetahui faktor-faktor yang menyebabkan timbulnya persitiwa tersebut" (Yulianti, 2018). Penelitian ini dilakukan di SMA Muhammadiyah Maumere dengan subjek penelitian adalah siswa SMA Muhammadiyah sebanyak 250 siswa. Pengambilan sampel sebanyak 153 siswa menggunakan teknik Stratified Random Sampling. Darmawan (2013:147) Stratified Random Sampling atau sampel acak 
distratifikasikan merupakan pengambilan sampel secara acak dan berlapis, teknik pengambilan sampel ini dilakukan apabila populasi terdiri atas beberapa strata dan bertujuan agar setiap sampel yang diambil mecerminkan strata-strata tersebut, maka responden akan diambil secara acak dari setiap stratanya. Pengumpulan data menggunakan angket dan dokumentasi. Angket digunakan untuk mengukur kedisiplinan belajar dan motivasi belajar dalam bentuk instrumen pertanyaan sedangkan dokumentasi digunakan untuk memperoleh nilai rapor siswa semester ganjil. Uji instrumen angket menggunakan uji validitas dengan rumus Correlation Product Moment diperoleh hasil untuk semua item dinyatakan valid dimana nilai rhitung > rtabel. Analisis data dilakukan menggunakan analisis deskriptif, uji prasyarat analisis dan uji hipotesis yang dihitung menggunakan SPSS 23.

\section{HASIL DAN PEMBAHASAN}

Tabel 2. Hasil Analisis Deskriptif Variabel

\begin{tabular}{cccc}
\hline Deskriptif & $\begin{array}{c}\text { Kedisiplinan } \\
\text { Belajar }\end{array}$ & $\begin{array}{c}\text { Motivasi } \\
\text { Belajar }\end{array}$ & $\begin{array}{c}\text { Prestasi } \\
\text { Belajar }\end{array}$ \\
\hline Mean & 30,51 & 56,00 & 79,88 \\
\hline Std Deviation & 3,399 & 6,694 & 3,100 \\
\hline Maximum & 39 & 68 & 87 \\
\hline Minimum & 20 & 37 & 70 \\
\hline
\end{tabular}

Sumber: Data diolah menggunakan SPSS Version 23

Berdasarkan tabel di atas yang dihitung menggunakan SPSS 23 menunjukan bahwa nilai kedisiplinan belajar memiliki rata-rata 30,51, std deviasi 3,399, nilai maximum 39 dan nilai minimum 20. Nilai motivasi belajar memiliki rata-rata 56,00, std deviasi 6,694, nilai maximum 68 dan nilai minimum 37. Nilai prestasi belajar memiliki rata-rata 79,88, std deviasi 3,100, nilai maximum 87 dan nilai minimum 70 .

Hasil uji prasyarat analisis menggunakan SPSS 23 diperoleh hasil uji normalitas melalui Kolmogorov Smirnov diperoleh nilai Asym. Sig (2-tailed) 0,052 > 0,05 maka data terdistribusi normal. Uji linearitas diperoleh nilai signifikan 
kedisiplinan belajar 0,196>0,05 maka tidak terdapat hubungan linear sedangkan nilai signifikan motivasi belajar 0,001 < 0,05 maka terdapat hubungan linear. Uji multikolinearitas diperoleh nilai VIF 1,093 < 10,00 dan nilai Tolerance 0,915>0,10 maka tidak terjadi gejala multikolinearitas serta uji heteroskedastisitas diperoleh melalui Uji Glejser menunjukan nilai signifikan kedisiplinan belajar 0,131 > 0,05 dan nilai signifikan motivasi belajar 0,181 $>0,05$ maka tidak terjadi gejala heteroskedastisitas.

Setelah data memenuhi prasyarat analisis, kemudian dilakukan uji hipotesis. Hasil tersebut disajikan pada tabel dibawah ini:

Tabel 3. Rangkuman Hasil Analisis Regresi Linear Berganda

\begin{tabular}{|c|c|c|c|c|}
\hline \multicolumn{5}{|c|}{ Coefficients $^{\mathrm{a}}$} \\
\hline \multicolumn{2}{|c|}{ Model } & Unstandardizied Coeffic & $\mathrm{t}$ & Sig. \\
\hline \multirow[t]{3}{*}{1} & (Constant) & 85,980 & 32,242 & 0,000 \\
\hline & Kedisiplinan Belajar & 0,004 & 0,051 & 0,960 \\
\hline & Motivasi Belajar & $-0,111$ & $-2,893$ & 0,004 \\
\hline \multicolumn{5}{|c|}{ a Dependent Variabel: Prestasi Belajar } \\
\hline \multicolumn{5}{|c|}{ Anova $^{a}$} \\
\hline \multicolumn{2}{|c|}{ Model } & $\mathrm{F}$ & \multicolumn{2}{|l|}{ Sig. } \\
\hline \multicolumn{2}{|r|}{ Regression } & 4,527 & \multicolumn{2}{|l|}{$0,012^{\mathrm{b}}$} \\
\hline \multicolumn{5}{|c|}{ a Dependent Variabel: Prestasi Belajar } \\
\hline \multicolumn{5}{|c|}{ b Predictors: (Constant), Kedisiplinan Belajar, Motivasi Belajar } \\
\hline \multicolumn{5}{|c|}{ Coefficients $^{\mathbf{a}}$} \\
\hline \multirow{2}{*}{\multicolumn{2}{|c|}{ Model }} & \multicolumn{3}{|c|}{ Correlations } \\
\hline & & Zero Order & Partial & Part \\
\hline \multirow[t]{3}{*}{1} & (Constant) & - & - & - \\
\hline & Kedisiplinan Belajar & $-0,066$ & 0,004 & 0,004 \\
\hline & Motivasi Belajar & $-0,239$ & $-0,230$ & $-0,229$ \\
\hline \multicolumn{5}{|c|}{ a Dependent Variabel: Prestasi Belajar } \\
\hline \multicolumn{5}{|c|}{ Model Summary } \\
\hline \multicolumn{2}{|c|}{ Model } & R Square & \multicolumn{2}{|c|}{ Adjusted R Square } \\
\hline \multicolumn{2}{|r|}{$0,239 a$} & 0,057 & \multicolumn{2}{|c|}{0,044} \\
\hline
\end{tabular}

Sumber: Data diolah menggunakan SPSS Version 23

Berdasarkan tabel diatas menunjukan nilai persamaan regresi berganda adalah sebagai berikut:

$$
Y=85,980+0,004 X_{1}-0,111 X_{2}
$$


1. Pengaruh kedisiplinan belajar terhadap prestasi belajar siswa di SMA Muhammadiyah Maumere.

Berdasarkan hasil analisis uji t menunjukan nilai signifikan $>0,05(0,960>$ $0,05)$ dan nilai thitung $<$ ttabel sebesar 0,051 $<1,975$ serta nilai koefisien bernilai positif yaitu 0,004. Jadi dapat disimpulkan bahwa kedisiplinan belajar tidak berpengaruh signifikan terhadap prestasi belajar siswa di SMA Muhammadiyah Maumere. Hal ini bertolak belakang dengan teori yang dikemukakan oleh Moenir dalam (Chulsum, 2017) bahwa disiplin merupakan bentuk kepatuhan terhadap peraturan dan tata tertib. Ini berarti faktor lain yang mempengaruhi prestasi belajar siswa diluar faktor kedisiplinan lebih dominan dibandingkan kedisiplinan. Kedisiplinan yang tinggi tidak selalu dapat memberikan pengaruh yang positif terhadap prestasi belajar. Adanya banyak faktor yang dapat mempengaruhi prestasi belajar menimbulkan berbagai kemungkinan yang dapat menjadi siswa dapat meningkatkan prestasi belajarnya. Ketika kedisiplinan yang tinggi tidak memberikan pengaruh yang positif terhadap prestasi belajar siswa, salah satu kemungkinan yang dapat terjadi adalah semangat siswa dalam belajar lebih tinggi sehingga dapat meraih prestasi belajar yang baik. Temuan dalam penelitian ini sejalan dengan temuan yang dilakukan oleh Mukhammad Shobakhul Falakh dimana dalam penelitian tersebut disimpulkan bahwa secara parsial kedisiplinan belajar tidak berpengaruh signifikan terhadap prestasi belajar.

2. Pengaruh kedisiplinan belajar terhadap prestasi belajar siswa di SMA Muhammadiyah Maumere

Hasil analisis uji t menunjukan nilai signifikan $<0,05(0,004<0,05)$ dan nilai thitung $<$ ttabel sebesar $-2,893<1,975$ serta nilai koefisien bernilai negatif yaitu $-0,111$. Jadi dapat disimpulkan bahwa motivasi belajar berpengaruh negatif terhadap prestasi belajar siswa di SMA Muhammadiyah Maumere. Artinya jika motivasi belajar mengalami kenaikan, maka prestasi belajar akan mengalami penurunan. Koefisien bernilai negatif artinya pengaruh motivasi belajar 
terhadap prestasi belajar adalah negatif. Kenaikan motivasi belajar akan mengakibatkan penurunan pada prestasi belajar. Hal ini disebabkan oleh rendahnya rasa percaya diri siswa di dalam kelas ketika proses belajar mengajar berlangsung. Siswa yang tidak memiliki rasa percaya diri dalam kegiatan belajar menggambarkan motivasi belajarnya di dalam kelas misalnya malas berdiskusi (bertanya, berpendapat, dan menjawab pertanyaan dari teman dan guru), ribut di kelas, bermain gadget, tidak mengikuti pelajaran, tidak mengerjakan tugas, kurang memperhatikan materi yang dijelaskan dan sebagainya. Temuan dalam penelitian ini sejalan dengan temuan yang dilakukan oleh Fitranty Adirestuty dalam penelitian tersebut disimpulkan bahwa secara parsial motivasi belajar berpengaruh negatif terhadap prestasi belajar siswa

3. Pengaruh kedisiplinan belajar dan motivasi belajar terhadap prestasi belajar siswa di SMA Muhammadiyah Maumere.

Berdasarkan hasil analisis uji F menunjukan nilai signifikan $<0,05(0,012<$ 0,05) dan nilai Fhitung > Ftabel sebesar 4,527 > 3,06. Jadi dapat disimpulkan bahwa secara simultan kedisiplinan belajar dan motivasi belajar berpengaruh signifikan terhadap prestasi belajar siswa di SMA Muhammadiyah Maumere.. secara simultan besarnya pengaruh yang diberikan oleh kedua variabel terhadap prestasi belajar sebesar 5,7\%. Sisanya 94,3\% tidak diteliti pada penelitian ini. Selanjutnya besarnya pengaruh yang diberikan oleh setiap variabel sebesar 0,0016\% untuk kedisiplinan belajar dan 5,29\% untuk motivasi belajar. Dasar pemikiran yang mendukung temuan ini ialah kedisiplinan memiliki pengaruh terhadap prestasi belajar siswa begitu pula dengan motivasi belajar yang memiliki pengaruh terhadap prestasi belajar siswa. Jika kedisiplinan dan motivasi belajar tinggi maka prestasi belajar yang diraih juga baik. Oleh karena itu untuk mendapatkan prestasi belajar yang baik diperlukan adanya kedisiplinan yang tinggi dan mendukung siswa dalam belajar begitu pula dengan motivasi belajar yang tinggi. Secara simultan temuan dalam penelitian ini sejalan dengan temuan yang dilakukan oleh mukhammad 
shobakhul falakh dimana dalam penelitinnya disimpulkan bahwa terdapat pengaruh signifikan antara variabel kedisiplinan dan motivasi belajar terhadap prestasi belajar.

secara simultan besarnya pengaruh yang diberikan oleh kedua variabel terhadap prestasi belajar sebesar 5,7\%. Sisanya 94,3\% tidak diteliti pada penelitian ini. Selanjutnya besarnya pengaruh yang diberikan oleh setiap variabel sebesar 0,0016\% untuk kedisiplinan belajar dan 5,29\% untuk motivasi belajar.

\section{KESIMPULAN}

Kesimpulan yang dapat diambil dari pembahasan diatas yaitu: 1) Kedisiplinan belajar tidak berpengaruh signifikan terhadap prestasi belajar siswa di SMA Muhammadiyah Maumere. 2) Motivasi belajar berpengaruh negatif dan signifikan terhadap prestasi belajar siswa di SMA Muhammadiyah Maumere. 3) Kedisiplinan belajar dan motivasi belajar secara simultan berpengaruh signifikan terhadap prestasi belajar siswa di SMA Muhammadiyah Maumere

\section{DAFTAR RUJUKAN}

Adirestuty, Fitranty., 2017. Pengaruh Self-Efficacy Guru dan Kreativitas Guru Terhadap Motivasi Belajar Siswa dan Implikasinya Terhadap Prestasi Belajar Pada Mata Pelajaran Ekonomi. Jurnal Wahana Pendidikan, Vol. 4 , No.1, Hal. 54-67.

Afandi, R., 2011. Integrasi pendidikan karakter dalam pembelajaran IPS di sekolah dasar. PEDAGOGIA: Jurnal Pendidikan, 1(1), 85-98.

A.M. Sardiman. 2011. Interaksi dan Motivasi Belajar Mengajar. PT Rajagrafindo: Jakarta

Depdiknas., 2003. Undang-undang Nomor 20 Tahun 2003 tentang Sistem Pendidikan Nasional, Jakarta: Depdiknas.

Devi Yulianti., 2018. Pengaruh Lingkungan Keluarga dan Sarana dan Prasarana Belajar di Rumah terhadap Prestasi Belajar Siswa. Jurnal Gema Ekonomi, Vol. 8, No.2, Hal. 1247-1280.

Febrianti, L., \& Rachmawati, L., 2018. Pengaruh Kecerdasan Emosional dan Disiplin Belajar terhadap Hasil Belajar Siswa di SMA Negeri 3 Nganjuk. Jurnal Pendidikan Ekonomi (JUPE), 6(2). 
Feni., 2014. Perbandingan Prestasi Belajar Siswa Jalur Bina Lingkungan dan NonBina Lingkungan. Jurnal Kultur Demokrasi.

Hadinata, Priyatna., 2009. Iklim Kelas dan Motivasi Belajar Siswa SMA. Dalam Jurnal Psikologi. Vol 3 No 1. Jawa Barat: Universitas Gunadarma

Falakh, Mukhammad Shobakhul., 2016. Pengaruh Kedisiplinan dan Motivasi Belajar Terhadap Tingkat Prestasi Belajar Mahasiswa Jurusan Pendidikan Ilmu Pengetahuan Sosial Fakultas Ilmu Tarbiyah Dan Keguruan UIN Maulana Malik Ibrahim Malang. Skripsi. Malang: UIN Maulana Malik Ibrahim Fakultas Ilmu Tarbiyah Dan Keguruan.

Santrock, J. W., 2009. Educational Psychology (Psikologi Pendidikan). Translated By Diana Angelica. Jakarta: Salemba Humanika.

Pratiwi, N. K., 2017. Pengaruh Tingkat Pendidikan, Perhatian Orang Tua, Dan Minat Belajar Siswa Terhadap Prestasi Belajar Bahasa Indonesia Siswa Smk Kesehatan Di Kota Tangerang. Pujangga, 1(2), 31.

Tsani, I. L., Herawati, N. I., \& Istianti, T., 2016. Hubungan Pola Asuh Orang Tua Dengan Kemandirian Anak Usia Dini. Cakrawala Dini: Jurnal Pendidikan Anak Usia Dini, 7(2).

Kusuma, Zuhaira Laily., 2015. Pengaruh Motivasi Belajar Dan Kedisiplinan Belajar Terhadap Prestasi Belajar Mata Pelajaran Akuntansi Siswa Kelas XI Ips SMAN 3 Pati Tahun Pelajaran 2013/2014. Economic Education Analysis Journal, $4(1), 164-171$. 